\title{
Tingkat Kerentanan Wilayah Pesisir Kota Makassar Terhadap Pencemaran Sampah
}

\author{
Nurmawati ${ }^{1}$, Jonson Lumban Gaol${ }^{2}$, Marisa Mei Ling ${ }^{3}$
}

\begin{abstract}
Makassar is one of the major cities in Indonesia with the densest concentration of population in coastal areas so that the pressure on this region is quite high. One of the main problems of Makassar is the existence of trash continues to increase. This study aims to determine the vulnerability level of coastal Makassar against trash pollution. The research was conducted on the Moon from May to July 2015. The research location is the coastal area of Makassar which includes eight subdistricts, namely: Subdistrict Biringkanaya, Tamalanrea, Tallo, Ujung Tanah, Wajo, Makassar, Mariso, and Tamalate. The data used are primary data and secondary data. Primary data collected from surveys and direct observation to the study site while secondary data obtained from the study of literature and related institutions in the city of Makassar. The results showed coastal subdistrict of Makassar city high potential to impact trash pollution. The vulnerability of the coastal area of Makassar against trash pollution are in the high category (very vulnerable).
\end{abstract}

Keywords: environmental vulnerability index, pollution, trash, Makassar

\section{PENDAHULUAN}

Makassar merupakan salah satu kota di Indonesia dengan konsentrasi penduduk terpadat di wilayah pesisir. Berbagai macam aktivitas masyarakat terpusat di wilayah pesisir sehingga tekanan terhadap wilayah ini menjadi semakin besar. Salah satu permasalahan utama Kota Makassar adalah keberadaan sampah yang terus meningkat. Pada tahun 2014 mencapai 762 ton/hari atau sekitar $4.495 \mathrm{~m} 3 /$ hari dan meningkat drastis pada tahun 2015 menjadi 1.280 ton/hari atau $7.554 \mathrm{~m} 3$ /hari (Dinas Kebersihan Kota Makassar 2015). Volume sampah meningkat drastis seiring dengan meningkatnya jumlah penduduk dan aktivitas manusia yang semakin beragam. Sampah yang tidak dikelola dan terbuang bebas ke lingkungan akan menyebabkan terjadinya pencemaran. Pencemaran bersifat multiaspek dan saling berhubungan satu dengan yang lain.
Wilayah pesisir termasuk wilayah yang rentan terhadap pencemaran sampah. Sampah yang masuk ke perairan pantai dapat melalui proses run-off atau dibuang langsung oleh manusia. Hal ini dapat menyebabkan pendangkalan pantai dan perubahan beberapa parameter kualitas air (Samawi, 2007). Pencemaran sampah juga dapat mengurangi nilai estetika lingkungan pesisir, mengganggu pelayaran, membahayakan kehidupan biota dan lingkungan laut, merugikan masyarakat secara sosial ekonomi, membahayakan kesehatan manusia bahkan dapat menyebabkan kematian. Dampak lainnya adalah dapat mengangkut polutan organik yang persisten, menyebabkan sedimentasi, eutrofikasi (red tide) pada alga, kekurangan oksigen (anoxia), kontaminasi logam berat dalam rantai makanan, dan masuknya spesies asing (Barnes, 2002; Dahuri et al., 2001; Maso et al., 2003; Mato et al., 2001).

Penelitian ini dilakukan untuk menentukan tingkat kerentanan wilayah pesisir Kota

\footnotetext{
${ }^{1}$ Dosen Ilmu Kelautan, Universitas Nuku. email: nurmawati7989@gmail.com. HP.082189034375

${ }^{2}$ Departemen Ilmu dan Teknologi Kelautan, Intitut Pertanian Bogor

${ }^{3}$ Jurusan Teknik Lingkungan, Universitas Surya
} 
Makassar terhadap pencemaran sampah. Penelitian tentang kepekaan/kerentanan pantai/wilayah pesisir sudah banyak dilakukan dengan menggunakan beberapa metode yang berbeda. Penggunaan metode tersebut dapat disesuaikan dengan topik penelitian dan tujuan yang ingin dicapai. Metode yang digunakan dalam penelitian ini adalah metode Environmental Sensitivity Index (ESI) atau Indeks Kepekaan Lingkungan (IKL). Metode IKL awalnya hanya digunakan untuk menggambarkan nilai-nilai biologi, sosialekonomi, dan sosial-budaya pada wilayah pesisir terhadap tumpahan minyak (NOAA, 1997). Namun dalam perkembangannya, IKL dapat digunakan untuk menilai kepekaan wilayah pesisir terhadap polutan dan bahan pencemar lainnya, baik yang berasal dari sungai, pemukiman, maupun kegiatan-kegiatan di sekitar pantai. Oleh karena itu dalam penelitian ini metode IKL coba diaplikasikan terhadap pencemaran sampah dengan memodifikasi beberapa parameter dan kriteria kepekaan.

\section{METODE PENELITIAN}

Penelitian ini dilaksanakan pada Bulan Mei - Juli 2015. Lokasi penelitian merupakan kawasan pesisir Kota Makassar yang meliputi 8 kecamatan yaitu: Kecamatan Biringkanaya, Tamalanrea, Tallo, Ujung Tanah, Wajo, Ujung Pandang, Mariso, dan Tamalate.

Alat yang digunakan dalam penelitian adalah GPS (Geographical Positioning System), kamera, laptop, kuisioner, dan daftar isian sedangkan bahan yang digunakan adalah citra landsat 8, peta administrasi Kota Makassar, dan peta pendukung lainnya. Perangkat lunak (software) yang digunakan adalah perangkat lunak untuk GIS (Arcgis 10.1). Data primer yang digunakan merupakan hasil survei (wawancara) dan observasi langsung ke lokasi penelitian serta hasil pengolahan data citra satelit. Data sekunder diperoleh dari studi literatur dan beberapa instansi terkait di Kota Makassar. Data yang dikumpulkan dalam penelitian ini merupakan data yang berkaitan dengan parameter indeks kerentanan (Tabel 1).
Tabel 1 Jenis dan sumber data penelitian

\begin{tabular}{|c|c|c|c|}
\hline Jenis data & $\begin{array}{l}\text { Metode penguevoulan } \\
\text { dea }\end{array}$ & Samber data & Thene \\
\hline 1. Cita uatulit Landat \& & Stradi tiverata & latemat & 2016 \\
\hline 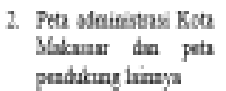 & Den selueder & $\begin{array}{l}\text { Bupoda Koea } \\
\text { Makauar }\end{array}$ & 2013 \\
\hline 3. Dewoyra & Den selueder & BPS Kot Motasar & $2013-2015$ \\
\hline $\begin{array}{l}\text { 4. Koneni gromba dn } \\
\text { Oneisisyas }\end{array}$ & $\begin{array}{l}\text { Data atander dn atad } \\
\text { ittrethuLepsen }\end{array}$ & $\begin{array}{l}\text { BP3 Kota Mtecanar } \\
\text { dat bieiret }\end{array}$ & $2013-2015$ \\
\hline $\begin{array}{l}\text { 5. Konesai Klim dan } \\
\text { cusa }\end{array}$ & Data relarder & BPS Keta Stakanar & $2013-2015$ \\
\hline 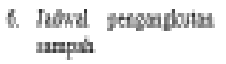 & Wrwacen & lasto & 2016 \\
\hline $\begin{array}{l}\text { 7. Vohane umpla dna } \\
\text { jualal TP5 }\end{array}$ & Data relandar & $\begin{array}{l}\text { Ditau Kaberihan } \\
\text { Koos Malesat }\end{array}$ & $2 \mathrm{N12}-2 \mathrm{N15}$ \\
\hline 8. Denaru & Den selueder & $\begin{array}{l}\text { BMKG Eoa } \\
\text { Malamar }\end{array}$ & $2014-2015$ \\
\hline 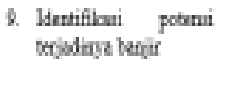 & $\begin{array}{l}\text { Wrwancera, data reluadr, } \\
\text { dat stodi literatu }\end{array}$ & $\begin{array}{l}\text { larin Bappeda Keta } \\
\text { Medassr, dy } \\
\text { incente }\end{array}$ & $\begin{array}{l}2016 \\
213-2 W 15\end{array}$ \\
\hline 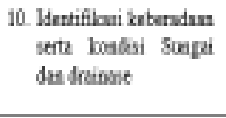 & $\begin{array}{l}\text { Wrwancen, data aluadr, } \\
\text { des stodi literatu }\end{array}$ & 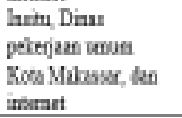 & $\begin{array}{l}216 \\
213-215\end{array}$ \\
\hline
\end{tabular}

Metode yang digunakan adalah metode Environmental Sensitivity Index (ESI) atau Indeks Kepekaan Lingkungan (IKL). Analisis IKL diinisiasi oleh National Oceanic and Atmospheric Administration (NOAA, 1997) yang diperuntukkan untuk pencemaran minyak. Selanjutnya dikembangkan oleh PKSPL IPB (2009) dan PKSPL IPB (2013).

Dalam penelitian ini dilakukan beberapa modifikasi IKL untuk aplikasi pencemaran sampah. Modifikasi yang dilakukan berupa pengembangan parameter tiap indeks dan penentuan nilai kepekaan untuk setiap parameter. Penyusunan parameter masing-masing indeks berdasarkan pendekatan sebab akibat yakni: penyebab munculnya sampah dan dampak yang ditimbulkan oleh sampah. Pengembangan ini mengacu pada beberapa sumber yang disesuaikan dengan data dan kondisi sebenarnya di lapangan. Penilaian kerentanan wilayah dilakukan dengan metode skoring (Tabel 1).

Indeks Kerentanan pesisir dihitung menggunakan rumus yang dikembangkan oleh PKSPL IPB (2013), yaitu:

$$
I K=\frac{\sum_{j=1}^{n} K K j}{n}
$$

Keterangan:

IK : Indeks Kerentanan, KKj : Nilai kerentanan parameter IK

$\mathrm{n} \quad$ : Jumlah parameter masing-masing indeks 
Nurmawati, dkk, Tingkat Kerentunan Wilayah...

Setiap parameter dari masing-masing indeks diklasifikasikan kedalam beberapa kriteria (nilai) yang selanjutnya diberi skor (rangking). Skor tersebut mulai dari 1 sampai 3, yang menandakan tingkat kerentanan rendah, sedang, dan tinggi. Dimana nilai indeks $1=$ rendah, nilai indeks $>1-2=$ sedang, dan nilai indeks $>2-3$ $=$ tinggi.

Tabel 2. Modifikasi matriks penilaian kerentanan lingkungan pesisir Kota Makassar

\begin{tabular}{|c|c|c|c|c|}
\hline \multirow{2}{*}{ Parameter } & \multicolumn{3}{|c|}{ Nillai kerentanan } & \multirow{2}{*}{ Acuan } \\
\hline & 1 & 2 & 3 & \\
\hline \multicolumn{5}{|l|}{ Indeks kerentanan $(\mathbb{K})$} \\
\hline $\begin{array}{l}\text { 1. Kepadatan penduduk } \\
\text { (jiwa } / \mathrm{km} 2)\end{array}$ & $\begin{array}{l}<15000 \\
\text { (Jarang) }\end{array}$ & $\begin{array}{l}15000-20000 \\
\text { (Sedang) }\end{array}$ & $\begin{array}{l}20000-40000 \\
\text { (Padat) }\end{array}$ & $\begin{array}{l}\text { SNI } 03-1733- \\
2004\end{array}$ \\
\hline $\begin{array}{l}\text { 2. Volume sampah } \\
\text { (liter oranghari) }\end{array}$ & $<3.25$ & $3.25-5$ & $>5$ & $\begin{array}{l}\text { Modifikasi SNI } \\
\text { 19-3983-1995 }\end{array}$ \\
\hline 3. Jumlah TPS & $\begin{array}{l}\text { Cukup }(3200 \\
\left.\text { orang } / 6 \mathrm{~m}^{3}\right)\end{array}$ & $\begin{array}{l}\text { Kurang }(>3200- \\
\left.6400 \text { orang } / 6 \mathrm{~m}^{3}\right)\end{array}$ & $\begin{array}{l}\text { Sangat kurang (> } \\
\left.6400 \text { orang } / 6 \mathrm{~m}^{3}\right)\end{array}$ & $\begin{array}{l}\text { Modifikasi SNI } \\
\text { 3242:2008 }\end{array}$ \\
\hline $\begin{array}{l}\text { 4. Jadwal pengangkutan } \\
\text { sampah }\end{array}$ & Setiap hari & $2-3 x /$ minggu & 1x/minggu & $\begin{array}{l}\text { Modifilkasi SNI } \\
\text { 19-2454-2002 } \\
\text { Modifikasi }\end{array}$ \\
\hline 5. Saluran air ke laut & Tidak ada & Drainase & Sungai dan drainase & $\begin{array}{l}\text { Wibowo A dan } \\
\text { Supriatna, } 2011\end{array}$ \\
\hline 6. Potensi daerah banjir & Tidak ada & Jarang $(2-4 x$ tahun $)$ & Sering ( $>4 x$ tahun $)$ & $\begin{array}{l}\text { Modifilkasi } \\
\text { Wibowo, } 2009\end{array}$ \\
\hline 7. Arus (meter/detik) & $>1$ (Cepat) & $0.25-1$ (Sedang) & $<0.25$ (Lambat) & $\begin{array}{l}\text { Modifikasi } \\
\text { Mason, } 1981\end{array}$ \\
\hline
\end{tabular}

Keterangan: $1=$ Rendah, $2=$ Sedang, $3=$ Tinggi

\section{HASIL DAN PEMBAHASAN}

Kota Makassar merupakan dataran rendah dengan ketinggian yang bervariasi antara 1-25 meter di atas permukaan laut, terletak pada posisi $119^{\circ} 24^{\prime} 17.38^{\prime \prime}$ BT dan $5^{\circ} 8^{\prime} 6.19^{\prime \prime}$ LS. Luas wilayah Kota Makassar seluruhnya adalah $175,77 \mathrm{~km} 2$ daratan, termasuk 11 pulau didalamnya dan luas wilayah perairan $\pm 100 \mathrm{~km}^{2}$. Batas administrasi Kota Makassar meliputi bagian utara dan timur berbatasan dengan Kabupaten Maros, bagian selatan berbatasan dengan Kabupaten Gowa dan Takalar, dan bagian barat berbatasan dengan Selat Makassar. Wilayah administrasi Kota Makassar terdiri dari 14 kecamatan, 8 diantaranya merupakan kecamatan pesisir (Kecamatan Biringkanaya, Tamalanrea, Tallo, Ujung Tanah, Wajo, Ujung Pandang, Mariso, dan Tamalate). Wilayah pesisir Kota Makassar terbagi ke dalam tiga kawasan, yaitu: pesisir bagian selatan sebagai kawasan perekonomian dan pariwisata, pesisir bagian tengah sebagai kawasan pelabuhan dan industri, serta pesisir bagian utara sebagai kawasan konservasi tanaman mangrove. Potensi besar yang dimiliki Kota Makassar adalah keberadaan ekosistem pesisir yang lengkap mulai dari ekosistem mangrove, estuaria, lamun, hingga terumbu karang. Hal tersebut turut menunjang potensi perikanan dan pariwisata di Kota Makassar.

\section{Indeks Kerentanan (IK) Pesisir Kota Makassar}

Indeks kerentanan merupakan salah satu komponen utama dalam menentukan indeks kepekaan lingkungan. Penilaian indeks kerentanan berdasarkan fakor fisik dan kelompok individu yang mengacu pada literatur dan kondisi lapangan. Parameter kerentanan pesisir terhadap pencemaran sampah adalah kepadatan penduduk, volume sampah, jadwal pengangkutan sampah, jumlah TPS, saluran air ke laut, potensi daerah banjir, dan arus.

Tabel 3. Data indeks kerentanan pesisir Kota Makassar

\begin{tabular}{|c|c|c|c|c|c|c|c|c|c|}
\hline No & \multicolumn{2}{|c|}{$\begin{array}{l}\text { Nama } \\
\text { kecamatan }\end{array}$} & $\begin{array}{l}\text { Kepadatan } \\
\text { rendoduk. } \\
\text { (jiwa lmi') }\end{array}$ & $\begin{array}{l}\text { Volume } \\
\text { smpah } \\
\text { (lorght }\end{array}$ & $\begin{array}{l}\text { Jumb } \\
\text { L TPS }\end{array}$ & $\begin{array}{l}\text { Jadozal } \\
\text { andsut } \\
\text { sampoh }\end{array}$ & $\begin{array}{l}\text { Salorat } \\
\text { air be } \\
\text { Lux }\end{array}$ & $\begin{array}{l}\text { Potes: } \\
\text { ibaniji }\end{array}$ & $\begin{array}{l}\text { Arvs } \\
\text { (mis) }\end{array}$ \\
\hline 1 & \multicolumn{2}{|c|}{ Biringkanaya } & $407 T$ & 395 & 22 & $\begin{array}{l}1 \mathrm{x} \\
\text { /mingere }\end{array}$ & $\begin{array}{l}\text { Sungai } \\
\text { drainase }\end{array}$ & Sering & 0.11 \\
\hline 2 & \multicolumn{2}{|c|}{ Tamalectea } & 3481 & 3.09 & 7 & $\begin{array}{l}\text { Setiap } \\
\text { ban }\end{array}$ & $\begin{array}{l}\text { Sungai } \\
\text { drainase }\end{array}$ & Sering & 0.11 \\
\hline 3 & \multicolumn{2}{|l|}{ Tallo } & 23773 & 589 & 12 & $\begin{array}{l}\text { Setiop } \\
\text { has }\end{array}$ & $\begin{array}{l}\text { Sungi } \\
\text { drainase }\end{array}$ & Sering & 0.11 \\
\hline 4 & \multicolumn{2}{|c|}{ Ujueg Tanah } & 828 & 697 & 2 & $\begin{array}{l}\text { Setiop } \\
\text { hani }\end{array}$ & $\begin{array}{l}\text { Kanal } \\
\text { draimas }\end{array}$ & Jang & 0.11 \\
\hline 5 & \multicolumn{2}{|l|}{ Wais } & 15438 & 695 & 11 & $\begin{array}{l}\text { Setiap } \\
\text { hasi }\end{array}$ & $\begin{array}{l}\text { Drainas } \\
\text { e }\end{array}$ & Jang & 0.11 \\
\hline 8 & \multicolumn{2}{|c|}{$\begin{array}{l}\text { Ujus: } \\
\text { Pandang }\end{array}$} & 10752 & 6.31 & 6 & $\begin{array}{l}\text { Setiap } \\
\text { han }\end{array}$ & Drailas & Jacang & 0.11 \\
\hline$\tau$ & \multicolumn{2}{|c|}{ Mariso } & 32316 & 5.60 & 10 & $\begin{array}{l}2-3 x \\
\text { /mingge }\end{array}$ & $\begin{array}{l}\text { Kanal } \\
\text { drainase }\end{array}$ & Jacang & 0.11 \\
\hline 8 & \multicolumn{2}{|c|}{ Tamalate } & 9436 & 553 & 25 & $\begin{array}{l}1 \mathrm{x} \\
\text { minggo }\end{array}$ & $\begin{array}{l}\text { Sungai, } \\
\text { kanvi, } \\
\text { draimas }\end{array}$ & Sering & 0.11 \\
\hline \multirow[t]{5}{*}{ Sun } & iber & : & Badan & Pusat & & tistik, & Dina & & \\
\hline & & Per & manan & dan & Keb & rsihan, & Dina & & \\
\hline & & Pek & rjaan & Umuı & & serta & Bada1 & & \\
\hline & & $\mathrm{Me}$ & orologi & Klima & tolo & dan $\mathrm{C}$ & ofisik & & \\
\hline & & $\begin{array}{l}\text { Kot } \\
\text { dat }\end{array}$ & Makas & sar; H & asil & $\begin{array}{l}\text { urvei, } \\
2015,\end{array}$ & $\begin{array}{l}\text { analisi } \\
016) \text {. }\end{array}$ & & \\
\hline
\end{tabular}


Tabel 4. Nilai indeks kerentanan pesisir Kota Makassar

\begin{tabular}{|c|c|c|c|c|c|c|c|c|c|}
\hline \multirow[b]{2}{*}{$\begin{array}{l}N \\
0\end{array}$} & \multirow[b]{2}{*}{$\begin{array}{l}\text { Nama } \\
\text { keccamatan }\end{array}$} & \multicolumn{7}{|c|}{ Skor:Parameter } & \multirow[b]{2}{*}{$\mathbb{K}$} \\
\hline & & $\begin{array}{l}\text { Kepadatan } \\
\text { pendudulu }\end{array}$ & $\begin{array}{l}\text { Volume } \\
\text { sampah }\end{array}$ & $\begin{array}{l}\text { Jumlal } \\
\text { TPS }\end{array}$ & $\begin{array}{l}\text { Jadwal } \\
\text { anglut } \\
\text { sampah }\end{array}$ & $\begin{array}{l}\text { Saluran } \\
\text { air ke } \\
\text { laut }\end{array}$ & $\begin{array}{l}\text { Potennsi } \\
\text { banjiir }\end{array}$ & Arus & \\
\hline 1 & Biringlanaya & 1 & 2 & 3 & 3 & 3 & 3 & 3 & 2.57 \\
\hline 2 & Tamalanrea & 1 & 1 & 3 & 2 & 3 & 3 & 3 & 2.29 \\
\hline 3 & Tallo & 3 & 3 & 3 & 2 & 3 & 3 & 3 & 2.86 \\
\hline 4 & Ujung Tanah & 1 & 3 & 3 & 2 & 2 & 2 & 3 & 2.29 \\
\hline 5 & Wajo & 2 & 3 & 1 & 2 & 2 & 2 & 3 & 2.14 \\
\hline 6 & $\begin{array}{l}\text { Ujung } \\
\text { Pandang }\end{array}$ & 1 & 3 & 2 & 2 & 2 & 2 & 3 & 2.14 \\
\hline 7 & Mariso & 3 & 3 & 2 & 2 & 2 & 2 & 3 & 2.43 \\
\hline 8 & Tamalate & 1 & 3 & 3 & 3 & 3 & 3 & 3 & 2.71 \\
\hline
\end{tabular}

\section{Kepadatan Penduduk}

Kecamatan dengan kepadatan penduduk tertinggi adalah Kecamatan Mariso dan terendah adalah Kecamatan Tamalanrea. Tabel 3 menunjukkan skor tertinggi untuk parameter kepadatan penduduk adalah Kecamatan Tallo dan Mariso (skor 3). Skor 3 menandakan kedua kecamatan memiliki tingkat kepekaan tinggi terhadap pencemaran sampah dilihat dari parameter kepadatan penduduk. Menurut aturan SNI (2004) tentang kepadatan penduduk, Kecamatan Mariso dan Tallo termasuk kategori penduduk padat $\left(>20.000 \mathrm{jiwa} / \mathrm{km}^{2}\right)$. Artinya jumlah penduduk yang ada di kecamatan tersebut sudah melebihi kapasitas luas wilayahnya. Semakin tinggi jumlah penduduk maka sampah yang dihasilkan juga meningkat. Pertambahan jumlah penduduk, perubahan pola konsumsi dan gaya hidup masyarakat mengakibatkan meningkatnya jenis, jumlah, dan keberagaman karakteristik sampah (Suarna, 2008). Namun disisi lain sampah yang tidak dikelola dengan benar akan berdampak negatif kepada manusia. Oleh karena itu, faktor penduduk sangat mempengaruhi kepekaan suatu wilayah terhadap pencemaran sampah. Menurut Wibowo dan Supriatna (2011), pencemaran dan tingkat kepekaan suatu wilayah akan semakin meningkat seiring dengan semakin tingginya jumlah penduduk.

\section{Volume Sampah}

Volume sampah Kota Makassar mengalami peningkatan setiap tahun. Peningkatan signifikan terjadi dari 761,61 ton $/ \mathrm{hr}$ (tahun 2014) menjadi 1279,97 ton/hr (tahun 2015) (Dinas Kebersihan Kota Makassar, 2015). Tabel 3 menunjukkan parameter volume sampah memiliki skor tertinggi (skor 3) pada 6 kecamatan yaitu: Kecamatan Tallo, Ujung Tanah, Wajo, Ujung Pandang, Mariso, dan Tamalate. Berdasarkan hasil analisis data, volume sampah yang ada di 6 kecamatan tersebut mencapai $>5$ 1/orang/hari. Menurut aturan SNI (1995) tentang spesifikasi timbulan sampah perkotaan; nilai tersebut telah melebihi standar aman bagi lingkungan. Artinya bahwa ke 6 kecamatan memiliki tingkat kepekaan tinggi terhadap pencemaran sampah berdasarkan parameter volume sampah. Menurut Suarna (2008), peningkatan volume sampah dapat disebabkan oleh pertambahan jumlah penduduk, perubahan pola konsumsi dan gaya hidup masyarakat serta tingginya daya beli masyarakat terhadap barang kebutuhan. Umumnya, pencemaran timbul karena aktivitas manusia yang semakin variatif. Setiap individu menghasilkan sampah dan jumlahnya sebanding dengan tingkat konsumsinya terhadap barang yang digunakan. Namun tidak semua sampah yang dihasilkan dikelola dengan baik sehingga peluang terjadinya pencemaran tetap ada.

\section{Jumlah Tempat Penampungan Sementara (TPS)}

Keberadaan TPS dapat dijadikan sebagai pengontrol penyebaran sampah. Timbulan sampah akan terakumulasi dengan baik jika jumlah TPS sesuai dengan standar yang seharusnya. Sebaliknya jumlah TPS yang kurang atau bahkan tidak ada, mengindikasikan sampah di wilayah tersebut telah dibuang ke tempat lain sehingga akan peka terhadap pencemaran sampah. TPS yang ditemukan di lokasi penelitian sebanyak 95 kontainer, 91 kontainer (volume 6 $\mathrm{m} 3$ ) dan 4 kontainer (volume $10 \mathrm{~m} 3$ ) yang tersebar di 8 kecamatan. Jumlah tersebut tidak mengalami perubahan sampai tahun 2016. Menurut aturan SNI (2008) tentang Pengelolaan sampah pemukiman; jenis kontainer volume $6 \mathrm{~m} 3$ berkapasitas 3200 orang dan kontainer volume 10 $\mathrm{m} 3$ berkapasitas 5330 orang. 
Parameter jumlah TPS memiliki skor tertinggi (skor 3) di Kecamatan Biringkanaya, Tamalanrea, Tallo, Ujung Tanah, dan Tamalate (Tabel 3). Artinya kecamatan tersebut memiliki tingkat kepekaan tinggi terhadap pencemaran sampah berdasarkan jumlah TPS yang ada. Berdasarkan hasil analisis data jumlah TPS di kecamatan tersebut hanya mampu memenuhi kebutuhan sampah masyarakat $\pm 1 / 3$ dari jumlah penduduknya. Jumlah TPS yang sangat kurang berpotensi tinggi menimbulkan pencemaran lingkungan. Kekurangan TPS akan membentuk perilaku masyarakat untuk membuang sampah rumah tangganya di tempat lain. Hasil wawancara menunjukkan sekitar $20 \%$ responden membuang sampah rumah tangga di lingkungan tempat tinggalnya. Sampah yang terbuang bebas ke lingkungan tidak akan dikelola dengan baik sehingga dapat mencemari lingkungan.

\section{Jadwal Pengangkutan Sampah}

Tabel 3 menunjukkan sampah di Kecamatan Tamalanrea, Tallo, Ujung Tanah, Wajo, dan Ujung Pandang umumnya diangkut setiap hari. Sampah di Kecamatan Mariso dominan diangkut 2 - 3x/minggu. Kecamatan Biringkanaya dan Tamalate didominasi jadwal angkut sampah $1 \mathrm{x} /$ minggu. Menurut aturan SNI (2002) pengangkutan sampah yang aman sebaiknya dilakukan setiap hari namun untuk kondisi tertentu bisa dilakukan 2 - $3 \mathrm{x}$ pengangkutan dalam sepekan. Jika melewati batas tersebut maka dikhawatirkan akan menimbulkan pencemaran seperti bau yang menyengat dan menjadi sarang berkembangnya bibit penyakit. Sampah rumah tangga umumnya bervariasi, sampah organik dan non organik namun dibuang dalam wadah yang sama sehingga kemungkinan menimbulkan bau tak sedap akan jauh lebih cepat. Tempat sampah rumah tangga memiliki kapasitas terbatas yang bahkan bisa penuh hanya dalam sehari. Jika petugas kebersihan tidak cepat tanggap maka disinilah peluang terjadinya pembuangan sampah di lingkungan sekitar. Sampah yang sudah penuh dan berbau tentunya akan dibuang secepatnya. Hal ini yang menjadikan jadwal pengangkutan sampah sangat berpengaruh terhadap timbulan sampah yang muncul di lingkungan sekitar.

Parameter jadwal angkut sampah memiliki skor tertinggi di Kecamatan Biringkanaya dan
Tamalate (tabel 4). Artinya dua kecamatan tersebut memiliki tingkat kepekaan tinggi terhadap pencemaran sampah berdasarkan parameter jadwal angkut sampah. Hasil analisis data menunjukkan rata-rata petugas kebersihan mengangkut sampah di kedua kecamataan tersebut sebanyak $1 \mathrm{x}$ dalam sepekan (setiap $\geq 5$ hari). Hal ini turut dipengaruhi oleh letak Kecamatan Biringkanaya yang berada di ujung utara kota dan Kecamatan Tamalate di ujung selatan kota. Jarak kedua kecamatan dari tempat pembuangan akhir (TPA) merupakan yang terjauh dibandingkan kecamatan lainnya. Menurut aturan SNI (2002) tentang Tata Cara Teknik Operasional Pengelolaan Sampah Perkotaan; salah satu faktor yang mempengaruhi sistem pengelolaan sampah perkotaan adalah jarak sumber sampah ke tempat pembuangan akhir. Namun sampah yang dibiarkan menumpuk lama berpotensi tinggi untuk mencemari lingkungan. Seperti menimbulkan bau yang menyengat, dikerumuni lalat sehingga nilai estetika lingkungan akan berkurang serta menjadi sarang berkembangnya bibit penyakit. Dampak yang ditimbulkan sampah tersebut menjadi pemicu masyarakat untuk segera membuang sampahnya bahkan ke tempat yang tidak seharusnya. Oleh karena itu, secara tidak langsung jadwal pengangkutan sampah turut mempengaruhi pola perilaku masyarakat terhadap sampah.

\section{Saluran Air ke Laut}

Berdasarkan proses terbentuknya saluran air terbagi dua yaitu saluran air alami (sungai) dan saluran air buatan (kanal, drainase, parit, selokan dan sejenisnya). Saluran air memiliki peran yang sangat penting yakni berfungsi untuk menyalurkan air hujan, air permukaan bahkan air pembuangan ke suatu tempat agar tidak menjadi masalah bagi lingkungan dan kesehatan. Namun disisi lain saluran air juga turut membawa sampah masuk ke perairan pesisir. Menurut Yosafat (2012), sampah yang sampai ke pantai berasal dari sungai/aliran air yang ada di wilayah tersebut. Sampah yang masuk ke perairan dapat menyebabkan sedimentasi, pendangkalan, dan menghalangi cahaya matahari masuk ke perairan. Selanjutnya dapat menghambat proses fotosintesis tumbuhan air dalam menghasilkan oksigen sehingga kondisi perairan akan 
kekurangan oksigen. Jika kondisi ini terus berlanjut, maka kehidupan organisme lain dapat terhenti. Cemaran yang masuk ke badan air pada akhirnya bermuara ke laut sehingga daerah yang dekat dengan sungai dan drainase akan lebih peka terhadap pencemaran sampah (Wibowo dan Supriatna, 2011).

Tabel 4 menunjukkan parameter saluran air memiliki skor tertinggi di Kecamatan Biringkanaya, Tamalanrea, Tallo, dan Tamalate. Secara geografis ke 4 kecamatan dilalui sungai. Berdasarkan hasil pengamatan ditemukan fungsi utama sungai-sungai tersebut sudah terganggu. Hal ini disebabkan beberapa spot tertentu telah terjadi penumpukan sampah dalam badan air terutama yang dekat dengan pemukiman. Selain itu didapatkan beberapa kanal yang tidak berfungsi maksimal. Diantaranya Kanal Jongaya di Kecamatan Tamalate dan Kanal Panampu di Kecamatan Ujung Tanah. Hal yang sama juga terjadi pada beberapa drainase yang ada dimasing-masing kecamatan. Sekitar 30\% saluran air yang ada di kecamatan pesisir Kota Makassar (terutama Kecamatan Biringkanaya, Tamalanrea, Tallo, dan Tamalate) tidak berfungsi dengan baik. Penyebab utama karena terjadi pendangkalan yang disebabkan oleh sedimentasi dan sumbatan sampah. Sampah yang masuk ke kanal akan menimbulkan bau yang menyengat, menjadi sarang berkembangnya bibit penyakit sehingga dapat mengganggu kesehatan manusia, dan menyumbat saluran air sehingga dapat memicu terjadinya banjir. Keadaan demikian akan menyebabkan sungai dan drainase meluap pada saat turun hujan sehingga bisa menimbulkan banjir.

\section{Potensi Daerah Banjir}

Dataran rendah merupakan wilayah yang paling dominan di Kota Makassar sehingga sebagian besar wilayah ini akan tergenang saat musim penghujan tiba. Kecamatan pesisir yang paling sering terkena banjir adalah Kecamatan Biringkanaya, Tamalanrea, Tallo dan Tamalate. Dilihat dari parameter potensi banjir, keempat kecamatan memiliki skor 3 yang berarti tingkat kepekaan terhadap pencemaran sampah lebih tinggi dibanding kecamatan lain. Hal ini turut dipengaruhi oleh banyaknya saluran air yang tidak berfungsi dengan baik. Salah satu penyebab utama yang paling sering ditemukan adalah adanya tumpukan sampah. Aliran air yang tidak lancar menjadi penyebab air tergenang dan lama kelamaan akan banjir jika hujan terjadi terus menerus. Fenomena banjir akan meluapkan air dari sungai dan drainase. Air yang meluap akan membawa tumpukan sampah didalamnya. Kondisi demikian dapat memicu berkembangnya bibit penyakit. Hal inilah yang menjadikan daerah yang terkena banjir peka terhadap pencemaran sampah. Selain itu intensitas hujan di Kota Makassar juga cukup tinggi. Rata-rata jumlah hari hujan mencapai 14 kali dalam sebulan dengan rata-rata curah hujan $238,89 \mathrm{~mm}$ selama kurun waktu tiga tahun (BMKG, 2015). Fenomena banjir juga didukung oleh daerah resapan air yang semakin berkurang. Berkurangnya daerah resapan air disebabkan oleh pembangunan yang cukup pesat.

\section{Kecepatan Arus}

Parameter arus mempunyai skor yang sama (skor 3) untuk semua kecamatan (Tabel 4). Secara umum kondisi arus dalam suatu wilayah memang relatif sama. Menurut Wibisono (2010), besar kecilnya arus disebabkan oleh beberapa faktor yaitu tiupan angin musim, suhu permukaan laut dan kecepatan angin. Kecepatan arus yang didapatkan pada lokasi penelitian rata-rata 0,10 $\mathrm{m} / \mathrm{s}$. Kecepatan arus ini digolongkan pada kecepatan arus lambat. Menurut Law et al. (2010), akumulasi sampah tertinggi ditemukan pada wilayah dengan kecepatan arus permukaan $<2 \mathrm{~cm} / \mathrm{s}$. Hal ini menandakan kecepatan arus yang relatif lemah dapat memicu penimbunan sampah dalam satu wilayah. Sebaliknya kecepatan arus kuat dapat memicu pergerakan sampah menjadi semakin jauh. Oleh karena itu, baik arus yang lemah maupun kuat memiliki tingkat kepekaan yang tinggi terhadap pencemaran sampah. Namun untuk wilayah pesisir, arus lemah jauh lebih peka terhadap pencemaran sampah dibanding arus yang kuat. Wilayah pesisir tidak hanya mendapat suplai sampah dari daratan utama tetapi juga dari tempat lain (sampah kiriman). Kondisi arus lemah tidak mampu mengembalikan sampah kiriman sehingga timbunan sampah akan meningkat. Selain merusak nilai estetika, timbunan sampah bisa menimbulkan bau yang menyengat dan menjadi sarang berkembangnya bibit penyakit, serta menganggu pelayaran. Menurut Jambeck et 
al. (2015), di daerah pesisir terjadi pembuangan sampah dan penerimaan sampah secara langsung sepanjang tahun. Sampah yang diterima merupakan sampah yang terbawa oleh arus maupun gelombang setiap hari. Hal ini menyebabkan adanya sampah di daerah pantai di seluruh dunia.

Tabel 4 menunjukkan nilai indeks kerentanan (IK) kecamatan pesisir Kota Makassar > 2. Artinya tingkat kerentanan kecamatan pesisir Kota Makassar terhadap pencemaran sampah termasuk tinggi. Menurut Wibowo dan Supriatna (2011), Kota Makassar merupakan salah satu kota pesisir di Indonesia yang lingkungan pantainya termasuk kategori sangat peka jika dilihat dari kepadatan penduduk, indeks sungai, dan tata guna lahannya.

Hasil pengamatan dan analisis data menunjukkan, pada umumnya kawasan pesisir Kota Makassar ditemukan banyak sampah. Kecamatan dengan kondisi pantai sudah mengalami pengerasan, tumpukan sampah terlihat jelas di perairan dan sekitarnya sedangkan kecamatan dengan kondisi pantai masih alami tumpukan sampah bisa ditemukan di banyak tempat seperti pantai, perairan, ekosistem, dan tanah kosong sekitar pantai. Lokasi sampahsampah tersebut merupakan tempat yang sulit dijangkau oleh petugas kebersihan. Oleh karena itu, sampah tersebut akan mengalami peningkatan secara terus menerus karena tidak ada proses pengangkutan dan pengelolaan sampah. Sampah yang paling banyak ditemukan adalah jenis sampah yang sulit terurai seperti plastik, kain, kaca, kaleng, besi, karet dan sebagainya sehingga gangguan yang akan ditimbulkan pada lingkungan akan tinggi (pencemaran tinggi).

Volume sampah tertinggi berada pada kawasan pesisir bagian tengah. Selain pemukiman dan infrastruktur yang padat, kawasan ini merupakan kawasan pelabuhan dan industri yang juga diapit oleh 2 kanal besar (Kanal Jongaya dan Panampu) serta Sungai Tallo. Beberapa dampak negatif yang ditimbulkan dari pencemaran sampah adalah dapat menyumbat saluran air, mengganggu kesehatan manusia (menjadi tempat berkembang biak bibit penyakit), mengurangi nilai estetika suatu kawasan, menghalangi proses fotosintesis tumbuhan air, menghalangi pertumbuhan batang mangrove karena terlilit sampah, memungkinkan tertutupnya pneumatophor yang berakibat pada kematian mangrove, mengurangi kadar oksigen di perairan, menyebabkan sedimentasi dan eutrofikasi sehingga bisa menimbulkan kematian pada beberapa organisme seperti plankton, ikan, kerang, dan bentos (Farida et al., 2015; Dahuri et al., 2001). Jumlah limbah padat terutama sampah plastik yang berpotensi sangat membahayakan semakin meningkat dan sekarang limbah tersebut juga dapat mengangkut polutan organik yang persisten (Mato et al., 2001), memicu munculnya spesies asing (Barnes, 2002) dan menyebabkan terjadinya red tide pada alga (Maso et al., 2003).

\section{KESIMPULAN}

Secara umum hasil penelitian menemukan tingkat kerentanan wilayah pesisir Kota Makassar terhadap pencemaran sampah berada pada kategori tinggi (Kecamatan Biringkanaya, Tamalanrea, Tallo, Ujung Tanah, Ujung Pandang, Wajo, Mariso, dan Tamalate). Hal ini berarti kecamatan pesisir Kota Makassar sangat rentan terhadap dampak pencemaran sampah dan berpotensi mengalami kerusakan yang tinggi baik secara ekonomi, sosial maupun ekologi.

\section{DAFTAR PUSTAKA}

Barnes, D.K.A. 2002. Invasions by marine life on plastic debris. Nature. 416:808809.doi:10.1038/416808a).

Barnes, D.K.A., F. Galgani, R.C. Thompson, and M. Barlaz. 2009. Accumulation and fragmentation of plastic debris in global environments. Phil. Trans. R. Soc. B. 364:

1985-1998. doi:10.1098/rstb.2008.0205.

Badan Metereologi Klimatologi dan Geofisika (BMKG). 2015. Data arus Kota Makassar tahun 2015. Makassar.

Badan Pusat Statistik (BPS). 2008. Sistem Neraca Sosial Ekonomi 2008. Jakarta.

Badan Pusat Statistik (BPS). 2016. Makassar dalam angka 2016. Makassar.

Badan Standardisasi Nasional (BSN). 1995. SNI 19-3983-1995. Spesifikasi timbulan 
sampah untuk kota kecil dan kota sedang di Indonesia. ICS 13.030.10.

Badan Standardisasi Nasional (BSN). 2002. SNI 19-2454-2002. Tata cara teknik operasional pengelolaan sampah perkotaan. ICS 27.180.

Badan Standardisasi Nasional (BSN). 2004. SNI 03-1733-2004. Tata cara perencanaan lingkungan perumahan di perkotaan. ICS 91.020; 91.040.30.

Badan Standardisasi Nasional (BSN). 2008. SNI 3242:2008. Pengelolaan sampah di permukiman. ICS 13.030.40; 91.190.

Dahuri, R., J. Rais, S.P. Ginting, dan M.J. Sitepu. 2001. Pengelolaan sumber daya wilayah pesisir dan lautan secara terpadu. Edisi Kedua. PT Pradnya Paramita, Jakarta.

Damar, A. 2008. Analisis Kepekaan Lingkungan Pesisir dan Laut. Lecturer Note. Program Studi Pengelolaan Sumberdaya Pesisir dan Laut. Sekolah Pasca Sarjana Institut Pertanian Bogor. Bogor.

Dinas Kebersihan dan Pertamanan Kota Makassar. 2015. Data sampah Kota Makassar tahun 2015. Makassar.

Farida, P.R., M. Fadli, A. Wijaya, dan D. Pandjisety. 2015. Analisis persoalan konservasi mangrove Wonorejo dalam ekonomi kota. Fakultas Teknik Sipil dan Perencanaan Institut Teknologi Sepuluh Nopember. Surabaya.

Jambeck, J.R., R. Geyer, C. Wilcox, T.R. Siegler, M. Perryman, A. Andrady, and K.L. Law. 2015. Plastic waste inputs from land into the ocean. Science. 347(6223):768-771.

Law, K.L., S. Morét-Ferguson, N.A. Maximenko, G. Proskurowski, E.E. Peacock, J. Hafner, C.M. Reddy. 2010. Plastic accumulation in the North Atlantic subtropical gyre. Science. 329(5996):1185-1188.

Maso, M., J. Garces, F. Pages, and J. Camp. 2003. Drifting plastic debris as a potential vector for dispersing Harmful Algal Blooms (HAB) species. Sci Mar. 67:107-111.

Mason, C.F. 1981. Biology of Freshwater Pollution. Longman. New York.
Mato, Y., T. Isobe, H. Takada, H. Kanehiro, C. Ohtake, and T. Kaminuma. 2001. Plastic resin pellets as a transport medium for toxic chemicals in the marine environment. Environ $\mathrm{Sci}$ Technol. $35: 318$ 324.doi:10.1021/es.001.04.98.

National Oceanic and Atmospheric Administration (NOAA). 1997. Environmental Sensitivity Index Guidlines Version 3.0. Seattle, Washington: NOAA Ocean Service.

Pusat Kajian Sumberdaya Pesisir dan Laut, Institut Pertanian Bogor (PKSPL-IPB). 2009. Sensitivity Area Mapping Project for Offshore and Onshore Operations. Bogor.

Pusat Kajian Sumberdaya Pesisir dan Laut, Institut Pertanian Bogor (PKSPL-IPB). 2013. Studi Indeks Kepekaan Lingkungan di Wilayah Kabupaten Seram Bagian Timur Maluku. Bogor.

Samawi, M.F. 2007. Desain sistem pengendalian pencemaran perairan pantai Kota Makassar (Studi kasus perairan pantai Kota Makassar). Disertasi. Institut Pertanian Bogor. Bogor.

Suarna, I.W. 2008. Model penanggulangan masalah sampah perkotaan dan pedesaan. Pusat Penelitian Lingkungan Hidup Universitas Udayana. Bali.

Wibisono, M.S. 2010. Pengantar Ilmu Kelautan. Edisi 2. Jakarta: Universitas Indonesia (UI-Press).

Wibowo, A. dan Supriatna. 2011. Kepekaan lingkungan pantai kota pesisir di Indonesia. Jurnal Ilmu dan Teknologi Kelautan Tropis. Vol. 3(2):1 - 20.

Wibowo, M. 2009. Pemetaan tingkat kepekaan lingkungan pesisir di Kota Semarang. Jurnal Hidrosfir Indonesia. Vol. 4(1): $17-22$.

Yosafat, F.C. 2012. Pergerakan Sampah Lautan dengan Pendekatan Model Trajektori Partikel di Perairan Selat Bali. Tesis. Institut Teknologi Bandung. Bandung. 